In low VAS group, $43 \%$ of the patients perceived low stress values vs $57 \%$ moderate-high. In VAS > 40 group $47 \%$ of the patients perceived low stress value vs $53 \%$ high-moderate. $80 \%$ of low-VAS $<$ group did not take anxiolytics and antidepressant drugs and for this cluster of patients was not recorded a VAS increase regardless of PSS. $16.7 \%$ of patients $(5 / 30)$ with VAS $<40$, taking anxiolytics / antidepressant medications and with a moderate-high PSS displayed an average increase of VAS pain by $20 \mathrm{~mm}$. In the VAS > 40 group a VAS variation was not recorded, regardless of taking anxiolytics / antidepressant medications and PSS. Conclusion: Lockdown impact on OA pain has been higher in the cluster of patients who were taking anxiolytics / antidepressant drugs with a moderate-high PSS. VAS pain increase in this cluster of patients exceeds minimal clinically relevant difference reported in literature ${ }^{1}$. A relevant physical activity decrease which might negatively impact on OA course has also been recorded.

REFERENCES:

11] Hawker G. et al. Measures of adult pain: Visual Analog Scale for Pain (VAS Pain), Numeric Rating Scale for Pain (NRS Pain), McGill Pain Questionnaire (MPQ), Short-Form McGill Pain Questionnaire (SF-MPQ), Chronic Pain Grade Scale (CPGS), Short Form-36 Bodily Pain Scale (SF-36 BPS), and Measure of Intermittent and Constant Osteoarthritis Pain (ICOAP). Arthritis Care Res (Hoboken), 2011.

Disclosure of Interests: Francesco Orsini: None declared, Orazio De Lucia: None declared, Francesca Ingegnoli: None declared, Gilberto Cincinelli: None declared, GIUSEPPE ARMENTARO: None declared, Raffaele Di Taranto: None declared, Roberto Caporali Speakers bureau: Abbvie, Amgen, BMS, Celltrion, Galapagos, Gilead, Lilly, Pfizer, Roche, UCB, Sanofi, Fresenius Kabi, Samsung bioepis, MSD, Consultant of: Galapagos, Gilead, Lilly, Janssen, MSD DOI: 10.1136/annrheumdis-2021-eular.2688

\section{AB0684 LESS THAN 20\% OF PATIENTS WITH A CHRONIC INFLAMMATORY RHEUMATIC DISEASE CHANGED THEIR IMMUNOSUPPRESSIVE MEDICATION BECAUSE OF THE COVID 19 PANDEMIC}

I. Andreica ${ }^{1}$, R. Jast ${ }^{1}$, G. Rezniczek ${ }^{2}$, U. Kiltz ${ }^{1}$, D. Kiefer ${ }^{1}$, B. Buehring ${ }^{1}$, X. Baraliakos ${ }^{1}$, J. Braun ${ }^{1}{ }^{1}$ Rheumazentrum Ruhrgebiet, Ruhr-Universität Bochum, Rheumatology, Herne, Germany; ${ }^{2}$ Marien Hospital Herne, Hospital of the Ruhr-University Bochum, Department of Obstretics and Gynecology, Research Lab, Herne, Germany

Background: The best treatment options of patients with chronic inflammatory rheumatic diseases (CIRD) in the pandemic have not been completely clear, especially in the beginning of the lockdown. Whether and to which degree pandemic-related therapy changes have occurred, has not been studied in detail.

Objectives: To study the behaviour of patients with CIRD initially facing the COVID 19 pandemic related to their disease status and medication.

Methods: Patients with CIRD were contacted by telephone to assess their health status and ask for changes in medication. Standardized assessment tools were used to assess disease activity, depression and anxiety. High disease activity was assumed if RADAI- $5 \geq 3.2$ and BASDAI $\geq 4$. Anxiety (HADS-A) and depression (HADS-D) of patients were assessed using HADS. A score $<8$ was taken as indication of no major problem in this regard.
Results: A total of 886 patients was interviewed between April 15 and June 15 of 2020 . Here we report on 550 patients with complete information on standard assessments (62\%). About $60 \%$ were female, mean age $54.4 \pm 13.7$, mean disease duration $12.2 \pm 10.5$ years. Most had spondyloarthritis $(\mathrm{SpA}, \mathrm{n}=287)$ including axial SpA (axSpA, $n=172)$ and psoriatic arthritis (PsA, $n=116)$, in total $52.2 \%$ while $40.2 \%$ had rheumatoid arthritis (RA, $n=221$ ), and $7.6 \%$ connective tissue diseases (CTD, $n=42$ ). Most RA patients were on methotrexate $(48.8 \%)$, while $43.8 \%$ took glucocorticoids. In addition, $61.0 \%$ of patients were on bDMARDs, mostly on TNF inhibitors (59.6\%). More SpA than RA patients were on bDMARDs: $71.0 \%$ vs $49.7 \%$ respectively. A recent change in medication was reported by 182 patients (33.1\%): 89 with RA (40.2\%), 88 with SpA (30.6\%) and 5 with CTD $(11.9 \%)$. Half of those who changed $(n=92 ; 50.5 \%)$ admitted that the change was mainly made due to fear of the pandemic ( $16.7 \%$ of all patients). Altogether, significantly more patients changed bDMARDs $(68.5 \%)$ than csDMARDs $(57.3 \%)$ The data of patients who changed vs patients who didn't change is shown in the Table 1, including subgroup analyses. The median HADS scores were $<8$. Conclusion: Two thirds of patients did not change medication but one third changed. A relatively high number of patients did so due to fear of the pandemic mostly those on biologics. There were no major differences between RA and $\mathrm{SpA}$. Anxiety and depression do not seem to play an important role for the decision to change medication (Table 1 below).

Disclosure of Interests: None declared

DOI: 10.1136/annrheumdis-2021-eular.2693

\section{AB0685 $\quad$ IMPACT OF COVID-19 ON PATIENTS WITH RHEUMATIC DISEASES: EXPERIENCE OF THE DEPARTMENT OF RHEUMATOLOGY OF THE UNIVERSITY HOSPITAL OF IBN ROCHD OF CASABLANCA}

H. El Moutaouakil ${ }^{1}$, Z. El Ouali ${ }^{1}$, K. Nassar ${ }^{1}$, S. Janani ${ }^{1}{ }^{1}$ University Hospital of Ibn Rochd, Department of Rheumatology, Casablanca, Morocco

Background: The COVID-19 outbreak has been a source of major concern for the management of rheumatic patients, particularly those under immunosuppressants. It is generally admitted that patients followed for autoimmune diseases have an increased risk of infectious complications compared to the general population (1). However, to date, there is no established relationship between autoimmune diseases and an increased risk of infection with SARS-CoV-2 (2)

Objectives: The primary objective was to assess the severity of COVID-19 in patients followed in our department. The secondary objective was to assess the subgroup of patients on immunosuppressants.

Methods: We conducted a descriptive retrospective study of patients followed in the Department of Rheumatology of the University Hospital of Ibn Rochd Casablanca. The patients who presented with COVID-19 between 08/2020 and 12/2020 were included. Epidemiological, clinical, therapeutic, and evolutionary data were collected and analyzed.

Results: Our series included 30 patients, with a sex ratio M/F of 0.3 . The mean age of the patients was 46.4 years $( \pm 16.3)$, with a mean follow-up time of 8.1 years. 7 patients had a metabolic syndrome. Patients were followed for rheumatoid arthritis $(n=4)$, spondyloarthritis $(n=10)$, systemic lupus erythematosus $(n=5)$, scleroderma $(n=2)$, polymyalgia rheumatica $(n=1)$, adult onset Still's

Table 1. RA and SpA patients who changed and who did not change their medication

\begin{tabular}{|c|c|c|c|c|c|}
\hline Group (N) / Reason & $\mathbf{N}$ & Active disease (\%) & $\begin{array}{c}\text { HADS-D } \\
\geq 8(\%)\end{array}$ & $\begin{array}{l}\text { HADS-A } \\
\geq 8 \text { (\%) }\end{array}$ & bDMARD therapy (\%) \\
\hline Rheumatoid arthritis & 221 & $134(60.6)$ & $76(35.0)[4]$ & 94 (43.3) [4] & $110(50.9)[5]$ \\
\hline Spondyloarthritis & 287 & $130(45.4)$ & $83(29.5)[6]$ & $109(38.8)[6]$ & 204 (72.6) [6] \\
\hline$P^{\text {a }}(\mathrm{RA}$ vs SpA $)$ & & $<0.001$ & 0.228 & 0.354 & $<0.001$ \\
\hline \multicolumn{6}{|c|}{ Patients did not change their medication } \\
\hline Rheumatoid arthritis (\%) & $132(59.7)$ & $84(63.6)$ & $46(35.9)[4]$ & $58(45.3)[4]$ & $62(48.4)[4]$ \\
\hline Spondyloarthritis (\%) & 199 (69.3) & $88(44.2)$ & $58(30.1)[6]$ & $69(35.8)[6]$ & $137(71.0)[6]$ \\
\hline$P(\mathrm{RA}$ vs $\mathrm{SpA})$ & 0.031 & $<0.001$ & 0.358 & 0.101 & $<0.001$ \\
\hline \multicolumn{6}{|c|}{ Patients changed their medication } \\
\hline Rheumatoid arthritis & 89 (40.3) & $50(56.2)$ & $30(33.7)$ & $36(40.4)$ & $48(54.5)[1]$ \\
\hline$P$ (vs no change) & & 0.331 & 0.846 & 0.567 & 0.457 \\
\hline Reason & [9] & & & & \\
\hline Pandemic & $41(51.3)$ & $15(36.6)$ & $11(26.8)$ & $14(34.1)$ & $24(60.0)[1]$ \\
\hline Inactive disease & $23(28.8)$ & $12(52.2)$ & $6(26.1)$ & $10(43.5)$ & $12(52.2)$ \\
\hline Active disease $^{\mathrm{b}}$ & $16(20.0)$ & $14(87.5)$ & $6(37.5)$ & $7(43.8)$ & $7(43.8)$ \\
\hline$P$ (reasons) & & 0.003 & 0.687 & 0.687 & 0.526 \\
\hline Spondyloarthritis & $88(30.7)$ & $42(47.7)$ & $25(28.4)$ & $40(45.5)$ & $67(76.1)$ \\
\hline$P$ (vs no change) & & 0.673 & 0.889 & 0.157 & 0.451 \\
\hline Reason & [6] & & & & \\
\hline Pandemic & $50(61.0)$ & $22(44.0)$ & $13(26.0)$ & $22(44.0)$ & $42(84.0)$ \\
\hline Inactive disease & $15(18.3)$ & $7(46.7)$ & $4(26.7)$ & $7(46.7)$ & $10(66.7)$ \\
\hline Active disease ${ }^{b}$ & $17(20.7)$ & $11(64.7)$ & $6(35.3)$ & $6(35.3)$ & $11(64.7)$ \\
\hline$P$ (reasons) & & 0.331 & 0.756 & 0.774 & 0.156 \\
\hline$P$ (RA vs SpA) & 0.031 & 0.294 & 0.950 & 0.603 & 0.004 \\
\hline
\end{tabular}

Data are presented as numbers (percentage proportions; across rows except for column $\mathrm{N}$ ) or medians (interquartile ranges). Missing values are in square brackets. ${ }^{a} \mathrm{P}$ values calculated using $\chi^{2}$ test or Mann-Whitney rank sum test. ${ }^{\mathrm{b}}$ Self-reported claim of disease activity. 
disease $(n=1)$, polyosteoarthritis $(n=6)$, benign osteopathy $(n=1) .17$ patients were in low disease activity when they presented the COVID-19. 8 patients presented moderate to high activity, of which $2(25 \%)$ developed a form requiring hospitalization. 7 patients were under NSAIDs, 13 under corticosteroids, 19 under csDMARD, 7 under bDMARD. The COVID-19 disease was symptomatic in $83 \%$ of cases, with fatigue $(68 \%)$, cough $(52 \%)$, back pain $(48 \%)$, anosmia $(48 \%)$, ageusia (44\%), arthritis (44\%), fever (36\%). The diagnosis was made with polymerase chain reaction $(83 \%)$, serology $(10 \%)$, CT scan $(23 \%)$. The CT lung lesions reached $25-50 \%$ in 2 lupus patients with a moderate disease activity, under corticosteroids and hydroxychloroquine. The involvement was $>75 \%$ in 2 patients, who admitted to intensive care: one was followed for polyarthrosis and was hypertensive and poorly balanced diabetic, and the other was followed for Horton's disease. The treatment was administered on an outpatient basis in $77.4 \%$ of cases, in an intensive care unit in $16 \%$ of cases. 30 patients fully recovered from infection, one patient died secondary to pulmonary embolism. The subgroup of patients on immunosuppressants consisted of 23 patients (76\%), of whom 5 (22\%) developed a moderate to severe form of COVID-19 requiring hospitalization. Among these hospitalized patients, 2 (40\%) had moderate to high disease activity of their rheumatism.

Conclusion: Most of the patients in our series presented a mild form of COVID19 , including those under immunosuppressants. Patients who were under hydroxychloroquine were not spared from COVID-19, but developed a mild form. The disease activity of the chronic rheumatism did not appear to influence the severity of the COVID-19.

REFERENCES:

[1] Grange L, Guilpain P, Truchetet M-E, Cracowski J-L. Challenges of autoimmune rheumatic disease treatment during the COVID-19 pandemic: A review. Therapies. 2020;75(4):335-42.

[2] Wu Z, McGoogan JM. Characteristics of and important lessons from the coronavirus disease 2019 (COVID-19) outbreak in China: summary of a report of 72314 cases from the Chinese Center for Disease Control and Prevention. Jama. 2020;323(13):1239-42

Disclosure of Interests: None declared

DOI: 10.1136/annrheumdis-2021-eular.2744

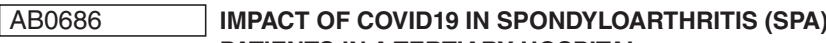 PATIENTS IN A TERTIARY HOSPITAL}

C. L. Garcia Gomez ${ }^{1}$, D. Montero ${ }^{1}$, L. Vega ${ }^{1}$, O. Ibarguengoitia ${ }^{2}$, I. Calvo ${ }^{2}$, C. E. Perez ${ }^{1}$, J. M. Blanco ${ }^{1}$, E. Galindez ${ }^{1}$, A. R. Inchaurbe ${ }^{1}$, M. E. Ruiz ${ }^{1}$, I. Torre ${ }^{1}$, E. Cuande ${ }^{1}$, I. Gorostiza ${ }^{3}$, M. R. Exposito-Molinero ${ }^{1}$, M. L. García Vivar ${ }^{1}$. ${ }^{1}$ Universitary Hospital of Basurto, Rheumatology, Bilbao, Spain; ${ }^{2}$ Hospital of Galdakao, Rheumatology, Galdakao, Spain; ${ }^{3}$ Universitary Hospital of Basurto, Investigation, Bilbao, Spain

Background: This tertiary hospital is the referall centre of 360.000 inhabitants, population with a Covid seroprevalence of $8,4 \%$ at final 2020 .

Since march, we have had a special concern for rheumatologic patients with systemic diseases and under inmunosupressive agents, including disease modifying antirheumatic drugs (DMARDs) and biological therapy (BT). This is why a special protocol for this population was set. It included performance of serology (CLIA test) for patients under BT and PCR and CLIA testing prior to new treatments. PCR testing was also generally performed: if symptomatology consistent with Covid; before hospitalisation; to tight contacts of infected people; and before procedures.

Objectives: To evaluate the impact of COVID-19 in our SpA patients in terms of severity of viral infection and its effect on SpA.

Methods: Data of $665 \mathrm{SpA}$ patients and confirmed Covid infection seen in our center from March 15th to December 15th was crossed. 3 miscoded patients with rheumatoid arthritis and 2 with non definite CLIA positivity were excluded. Finally 49 patients' clinical records were reviewed. Data regarding epidemiologic features, SpA characteristics, comorbidities, therapy received, clinical activity before and after Covid, and severity of the infection was collected. IBM SPSS v23 was used for statistical analysis.

Results: Among $49 \mathrm{SpA}$ patients, 59\% were male, mean aged 56,63 years (range 23-79). 62,2\% presented at least 1 comorbidity. $65 \%$ were psoriatic arthritis. They mostly had longstanding disease (median 10,5 years -range- 1 -35). Previously $63 \%$ had received DMARDs, mainly methotrexate, and $32 \% \mathrm{BT}$. When Covid was diagnosed $37,2 \%$ were under DMARDs and $53 \%$ under BT (69,2\% TNF inhibitors, $26,9 \%$ anti-II 17, 3,9\% ustekinumab). At this point, disease activity was controlled in $82 \%$ of patients $(39 \%$ in remission, and $43 \%$ in low disease activity state). Only $18 \%$ showed moderate activity.

Within the 49 patients, 34 were diagnosed by PCR and 15 by CLIA tests. 9 required hospitalisation, of whom 4 developed more severe disease ( 3 received glucocorticoid pulses and 2 tocilizumab). A woman with PsA under secukinumab presented pneumonia and PE. None required mechanical ventilation. There were no exitus.
Due to Covid infection 9 patients (50\%) stopped DMARDs treatment, (5 of them hospitalised). 9 patients withdrew BT after Covid diagnosis; $60 \%$ of the BT-hospitalised, and $28.5 \%$ of the BT- non-hospitalised. 1 suffered a flow with severe disease activity after withdrawal of II-17 inhibitor.

Conclusion: Prevalence of SARS cov 2 infection in SpA patients was not greater than in general population. Most were asymptomatic or suffered mild disease. Only 9 were hospitalised. Factors related to hospitalisation seem similar to those of general population, even if statistical significance was not found due to the small sample. BT does not seem to relate to hospitalisation in SpA and we had no deaths to date in them.

More studies should be made to throw out conclusions.

\begin{tabular}{|c|c|c|c|}
\hline $\begin{array}{l}\text { Baseline characteristics of SpA patients } \\
\text { with confirmed Covid19 }\end{array}$ & $\begin{array}{l}\text { Hospitalised } \\
\text { (N 9) }\end{array}$ & $\begin{array}{l}\text { Non-hospitalised } \\
\qquad(\mathrm{N} 40)\end{array}$ & Total (N 49) \\
\hline Mean age (range) $-\mathrm{yr}$ & $62,56(43-74)$ & $55,3(23-79)$ & $\begin{array}{c}56,63 \\
(23-79)\end{array}$ \\
\hline Male sex - no. (\%) & $6(66,6)$ & $23(57,5)$ & $29(59,1)$ \\
\hline $\begin{array}{l}\text { Smoking habit (active, ex-smokers) - no. } \\
(\%)\end{array}$ & $2(22,2)$ & $23(57,5)$ & $25(51)$ \\
\hline Non comorbidities - no. (\%) & $2(22,2)$ & $17(42,5)$ & $19(38,8)$ \\
\hline Hypertension - no. (\%) & $3(33)$ & $14(35)$ & $17(35)$ \\
\hline Diabetes - no. (\%) & $1(11)$ & $6(15)$ & $7(14,2)$ \\
\hline Dyslipidemia - no. (\%) & $4(44)$ & $9(22,5)$ & $13(26,5)$ \\
\hline Obesity (BMI >30) - no. (\%) & $4(44)$ & $12(30)$ & $16(32,7)$ \\
\hline $\begin{array}{l}\text { Chronic obstructive pulmonary disease } \\
- \text { no. (\%) }\end{array}$ & $2(22,2)$ & $4(10)$ & $6(12,2)$ \\
\hline Asthma - no. (\%) & $0(0)$ & $4(10)$ & $4(8,2)$ \\
\hline Cardiopathy - no. (\%) & $1(11,1)$ & $8(20)$ & $9(18,4)$ \\
\hline $\begin{array}{l}\text { Median disease time since diagnosis } \\
\text { (range) }-y r\end{array}$ & $14,5(7-20)$ & $10(1-35)$ & $10,5(1-35)$ \\
\hline \multicolumn{4}{|l|}{ SpA type } \\
\hline Psoriatic arthritis - no. (\%) & $8(88,8)$ & $24(60)$ & $32(65,3)$ \\
\hline Ankylosing spondylitis - no. (\%) & $1(11,1)$ & $15(37,5)$ & $16(32,7)$ \\
\hline Non-Rx ankylosing spondylitis - no. (\%) & $0(0)$ & $1(2,5)$ & $1(2)$ \\
\hline \multicolumn{4}{|l|}{ Current treatment when diagnosed ( $\mathrm{N} \mathrm{48)}$} \\
\hline DMARDs - no. (\%) & $6(66,6)$ & $12(30)$ & $18(37,5)$ \\
\hline BT - no. (\%) & $5(55,5)^{*}$ & $21(52,5)$ ** & $26(54,1)$ \\
\hline $\begin{array}{l}\text { * } 5 \text { anti-TNF ( } 1 \text { etanercept), } 2 \text { anti II-17, } \\
1 \text { anti II-12-23. }\end{array}$ & & & \\
\hline ** 12 anti-TNF ( 4 etanercept), 5 anti II-17. & & & \\
\hline
\end{tabular}

Disclosure of Interests: None declared

DOI: 10.1136/annrheumdis-2021-eular.2960

\begin{tabular}{|l|l|}
\hline AB0687 & EFFECT OF COVID-19 ON PATIENTS ATTENDING \\
AMBULATORY DEEP VENOUS THROMBOSIS OUT- \\
PATIENT CLINIC: A RETROSPECTIVE, COHORT \\
ANALYSIS[KI1] [KI1]101 CHARACTERS
\end{tabular}

T. Hill ${ }^{1}$, K. P. Iyengar ${ }^{1}$, A. Nune ${ }^{2} .{ }^{1}$ Southport \& Ormskirk Hospital NHS Trust, Trauma and Orthopaedics, Southport, United Kingdom; ${ }^{2}$ Southport \& Ormskirk Hospital NHS Trust, Rheumatology, Southport, United Kingdom

Background: COVID-19 has been acknowledged as an procoagulant disorde with increased risk of venous thromboembolism (VTE) [1]. High rates of VTE in patients admitted to intensive care unit have been reported [2]. However effect of COVID-19 on ambulatory patients attending out-patient clinics has not been described.

Objectives: This retrospective, observational cohort study analyses the impact of COVID-19 on incidence of Deep Venous Thrombosis (DVT) in patients referred to Ambulatory Deep Venous Thrombosis Out-patient Clinic (ADOC). A comparative analysis of patients attending ADOC during a similar period in 2019 is undertaken.

Methods: Patients who attended the ADOC with suspected DVT during the 'first wave' of the COVID-19 pandemic between 01 February and 30 June 2020 at Southport and Ormskirk NHS Trust were studied and compared to a similar period in 2019. Patients characteristics, comorbidities, risk factors, incidence of DVT and relationship with COVID-19 with the evaluation of haematological parameters including D-dimer and two- tier Wells score. Additionally we examined patients outcomes including morbidity, mortality and hospital admissions.

Results: Overall, there was a decrease in the number of patients attending the ADOC from 290 in 2019 to 233 in 2020 . However, a total of 38 patients tested positive for DVT, a rate of $16.3 \%$, which is compared to an incidence of $7.9 \%$ in 2019. Due to evolving protocols, the COVID-19 status of all patients attending the ADOC could not be ascertained. However, 5/233 of the 2020 cohort patients either had a positive test result $(n=4)$ or were symptomatic of COVID-19 $(n=1)$.

Conclusion: There has been a $129 \%$ increase in the incidence of DVT in patients presenting to ADOC at our trust during the 'first wave' of the COVID-19 